\title{
Project incubators and Enhancing Entrepreneurship
}

\author{
Diaa Ali Suliman AL Khresheh ${ }^{1}$, Mohammad Klaib Ibraheem Alsoub ${ }^{2}$ \\ Research Scholar Department of public science AMU ${ }^{1}$ \\ Research Scholar Department of public science $\mathrm{AMU}^{2}$
}

\begin{abstract}
The study is concerned with knowing the extent to which the incubated and graduated projects are affected by the services of the project incubator, through which it seeks to promote entrepreneurship. The problem of the study is represented in the following: Weak awareness of pioneer's businesses and trustee bodies for services provided by project incubators. The study found to a number of conclusions, the most important of which is that project incubators mainly aim to promote the spirit of entrepreneurship and support small entrepreneurial projects to face the difficulties of the launch stage. The study also found a number of among the recommendations, the most important of which is to emphasize and develop the services provided by the project incubator, in order to promote and spread the spirit of leadership among those in charge of its affiliated projects.
\end{abstract}

Keywords: project incubators, entrepreneurship

\section{INTRODUCTION}

In fact, small and medium enterprises are the locomotive that takes the economy of any country towards growth and prosperity, contrary to popular belief, the economies that pay special attention to small and medium-sized enterprises are the most developed economies are best able to solve the economic problems of their countries. The starting point in order to support this vital sector in the Jordanian economy lies in spreading and supporting the culture of self-employment in general, and the culture of entrepreneurship in particular. Despite the objective problems and obstacles that impede the progress of this sector towards prosperity, the obstacles and self-obstacles are the internal enemy that prevents this sector from starting to play its role. In addition, we find some projects, especially small ones, that lack a clear prior vision of the justifications for their existence, Its presence does not reflect a specific development policy, in addition to the fact that its establishment is not carried out within a well-defined development strategy, which necessitated finding an effective way to support these projects and extend a helping hand to them. It was created, effectively and successfully, in accelerating the implementation of economic development programs, technology and job creation by being a dynamic process to develop and develop business projects, especially those that are in the beginning stage of activity (LubicaLesáková, 2012). First: Project incubators and ingredients for the success of pioneering projects.

1- $\quad$ Project incubators and their economic roles.

Definition of project incubators:They are institutions that support entrepreneurs who have ambitious ideas and sound economic studies, and some of the resources necessary to achieve their ambitions, so as to provide them with an appropriate work environment during the critical first years of the project's life, increase the chances of success by completing the technical and administrative aspects at a nominal cost, and push the project owner to focus on the essence of the work for a specific period after which the relationship diminishes to turn into a new initiator(Salous, 2005).

The main objective of the incubation program is to breed successful start-up companies (graduates) that open up new opportunities for work and remunerative jobs, contribute to reviving economic and social conditions, and open markets for new technologies, modernity, and the creation of wealth for the national local economy.

The incubator's mission revolves around its quest to be a development and creativity center, working through a qualified administrative and technical cadre in order to develop the human capabilities of the initiators to start implementing promising investment projects that push the wheel of the economy forward.

\section{The economic roles of project incubators:}

Small and emerging entrepreneurial projects are exposed to many risks that may hinder their growth and development, and contribute to their failure and collapse, as experiences in many countries indicate that the success of small projects that are not

Its sponsorship in incubators drops to less than $50 \%$, while the success rate of small projects sponsored by incubators rises to more than $80 \%$. Therefore, incubators seek to:

- Encouraging the creation and development of new small projects: by providing all kinds of financial, administrative, and marketing support (Chiranjibi, 2006), sponsoring new projects in the stage of initiation and growth, 


\section{International Advanced Research Journal in Science, Engineering and Technology}

\section{Vol. 8, Issue 12, December 2021}

\section{DOI: $10.17148 /$ IARJSET.2021.81262}

and facilitating the start-up of small businesses, the project, reaching a community support network and establishing a set of distinct supportive services.

- Development of the local community: through the development and development of the surrounding business environment, and making the incubator a nucleus of development regional and local, and a center for spreading the spirit of self-employment among the masses of young people wishing to join the labor market(Tornatzky Louis and all, 2002).

- $\quad$ Supporting industrial and technological development: Technology incubators focus on nurturing and developing innovative ideas and applied research, and transferring them from the research and development stage to the implementation stage, setting up technology incubators specialized in specific sectors that facilitate the transfer and localization of modern and advanced technology and focus on developing the technologies of these sectors.

- $\quad$ Supporting and developing human resources and creating opportunities: Develop the skills, entrepreneurial spirit and ability to manage the project represents the most important effects of the presence of project incubators in any society in addition to working on creating job opportunities.

2- The basic ingredients for the success of incubated projects

Practitioners and experts recognize that there must be certain key elements to the success of incubators, from which a quality incubator develops over time.

According to the scientific reports of the incubators, there are basic criteria that must be taken into account to ensure the success of the incubator's work to develop and accelerate the establishment of projects with high growth or added value, in the economic environment and surrounding communities.

The incubator manager and his connection to the business in the incubator: The incubator manager has a direct impact on the success of the incubator and the projects attached to it, so he must work and understand with the owners of the projects and help them developtheir projects(Krzysztof Zasiadly, 2010) the management of incubators needs a special personality with practical and leadership experience and the ability to deal with individuals and form networks of relationships on a permanent and successful basis.

The accuracy of the selection and the existence of a clear policy for entering and graduating from the incubator: providing a transparent and flexible policyand openness, which describe the type of innovators and investors that incubator environments try to attract maintaining and developing them, by setting clear criteria for entering the incubator and the stage of graduation( European Commission,2002)

Appropriate presence of the service provided by the incubator: designing and specifying the appropriate services and support required for the incubators based on what the work requires, is essential for the success of the incubator's work to identify and facilitate the required funding and link marketing and appropriatecommunications, specific technical and commercial advice and skills required by entrepreneurs, as well as developing a good business plan and other necessary needs that the beneficiary of the incubator needs.

\section{Second: Entrepreneurship and the factors for its advancement.}

\section{1- $\quad$ Entrepreneurship: Definition and Developmental Implications.}

Definition of Entrepreneurship: Although there is a convergence of views on the term entrepreneurship and the dimensions it covers, the most of the scientists and researchers did not put a definitive definition, and most of them revolved around taking risks, creativity and innovation (R.Histrich\& P. Mechae, 2006).

Leadership means exclusivity and reliance on difference, diversification and compatibility and new methods, and do not depend on the prevailing models and habits that others do, but rather it is the access to unique and new products and methods that do not match the usual methods or the established methods.

\section{The developmental effects of entrepreneurship:}

Entrepreneurship is a dynamic process to secure the accumulation of wealth that is provided by individuals. The concept of entrepreneurship must be viewed with some flexibility, because we find a discrepancy in the concept between developed and developed countries in developing countries, it is linked to inventions and exclusivity.

As for the developing countries, whoever takes the initiative and moves, takes risks and creates a new business, through which he works to contribute to the goals of economic and social development, is considered a pioneer. The role of leadership in economic and social development in general can be summarized as follows:

- Raising the level of productivity.

-Technology transfer.

- Creating new job opportunities.

-Finding new markets.

-Contribute to the diversification of production due to the different fields of creativity of the entrepreneurs.

-Increasing the ability to compete through accurate and conscious knowledge of the local environment and the environment external and the development of working methods through it and interacting with it positively.

- Renewal and restructuring in economic projects. 


\section{International Advanced Research Journal in Science, Engineering and Technology}

\section{Vol. 8, Issue 12, December 2021}

\section{DOI: $10.17148 /$ IARJSET.2021.81262}

The main factors for the advancement of new entrepreneurial projects.

Most of the specialized studies indicate that entrepreneurship arises from a group of different factors, and they have been classified in two main groups, internal factors and external factors associated with the creation of new projects (EuroMediterranean Summitfor economic and social councils and institutions,2009).

\section{Internal factors:}

The internal factors are based on the behavior that leads us towards leadership, given that the positive behavior among individual's society can be taken as a good indicator of the potential and disadvantages of business effectiveness in societies.

The behavior most closely related to the business world is the one that provides information on motives (perception of business opportunities, awareness of

Risks, awareness of capabilities to create a company) to create a new company.

Perception plays a major role in searching for and seizing available opportunities in the market in which the organization operates.

This role is played by entrepreneurs in developed countries, but in countries with low levels of economic development, the entrepreneurial activity emerges as a strategy to overcome unemployment.

The perception of risk is another determinant, when creating a new company that is influenced by the inclinations of individuals and organizations and the extent of returns the expected amount of this risk, and therefore it is necessary to realize these risks by reading and analyzing all of them circumstances and variables surrounding the external environment, and reliance on information related to the tendency towards risk.

Feeling the ability to face the challenges of creating and consolidating a company is important when realizing a business opportunity an essential factor for personnel training.

\section{External factors}

The division of factors related to the social, political and economic context is essential to know the aspects that should be covered by the policies aimed at promoting the creation and consolidation of business.

Entrepreneurial activity differs from one country to another and is due to the economic characteristics, support and encouragement mechanism such as activating the intellectual property rights law, taxes and economic incentives, and financial development.

GnyawaiietFogel has set a general framework for the entrepreneurial environment and encouragement in society through the following dimensions:

Government policies and procedures: Facilitating and simplifying procedures for entrepreneurs facilitates the start of the project and reduces many obstacles that stand in the way. Here comes the role of the government, which directly affects the various market mechanisms, and the mechanism of demand and supply in it.

Economic and social conditions: highlights the effective role of economic and social factors in promoting leadership in society through the provision of loans and their facilities, technical assistance to entrepreneurs, facilities and consultations, and the provision of various information related to their projects. Leadership and its benefits.

Administrative entrepreneurial skills: management skills, marketing and financial skills,and intellectual skills are considered creativity is important for the entrepreneur, and this is to enable him to face the various circumstances and developments that encounter the project he manages or owns, and here the importance of training and educational programs provided by the community to refine leadership skills and development.

The financial support provided to the project: The financial resources are one of the most important sources for the success of the project, so the lack of this type of resources will be an obstacle for the entrepreneur to start his project, if he does not find financial help, which he needs for several purposes such as avoiding risks, financing the project, accumulating capital and others. Banks are one of the most important sources Financing for small projects, as well as we find that the entrepreneur can obtain the necessary financing from suppliers by relying on commercial credit.

Support and advisory and technical assistance: Support here means social support, which includes the material and moral support that a person can obtain and the facilities granted by the authorities that have the right to accept or reject these projects.

\section{CONCLUSIONS:}

1- Most of the definitions of leadership revolve around a set of concepts and facts, including:

- Entrepreneurship includes innovation and creativity of new ideas, and the initiative in putting them into practice Through the compatibility of resources of different types in the organization.

- $\quad$ Realizing that the phenomenon of entrepreneurship cannot be isolated from many other phenomena associated with it, such as

(Culture, education, training, finance, creativity) in the economic and social context in which it exists. 


\section{International Advanced Research Journal in Science, Engineering and Technology}

Vol. 8, Issue 12, December 2021

DOI: 10.17148/IARJSET.2021.81262

2 - Institutional incubators mainly aim to promote the spirit of entrepreneurship and support entrepreneurial projects small to face the difficulties of the starting stage.

Recommendations:

1. Emphasis on the services provided by the project incubator to overcome the difficulties in front of the projects incubated, in order to promote and spread the spirit of leadership among those in charge of these projects.

2. Develop the services of the project incubator, taking into account the deficiencies that may surround it, through focus on her at work.

3. The project incubator should establish alliances with scientific organizations and universities and encourage open communication between business sectors and relevant parties, to provide a productive and stimulating environment for entrepreneurship.

4. Providing appropriate opportunities for training incubated project owners on a culture of risk tolerance spreading the philosophy of the initiative.

\section{REFERENCES}

1- LubicaLesáková,(2012)," The Role of Business Incubators in Supporting theSME Start-up”, ActaPolytechnicaHungarica, Vol. 9, No. 3: 85-95.

2- Chiranjibi,( 2006),'Strategy For Promoting business Incubation Centers in Nepal”, Economic Policy Network, policy paper 21.

3- European Commission, (2002),' Benchmarking of business Incubators',Centre for strategy \& evaluation services.

4- Krzysztof Zasiadly,(2010)," Business Incubator Model Business Road Map 2020”, USAID MEP, Kazakhstan.

5- Tariq Abdel Salam Al-Salous, (2005), (Business Incubators), Dar Al-Nahda Al-Arabiya, Cairo.

6- Tornatzky Louis and all,(2002), "A National Benchmarking Analysis of Technology Business Incubator Performance and Practices" The National Business Incubator Association, USA. 